\title{
ELLEIEC Project: A contribution to harmonise the European Higher Education Area
}

\author{
Hamed Yahoui ${ }^{1}$,Olivier Bonnaud ${ }^{2}$, Helene Frémont ${ }^{3}$, Anna Friesel ${ }^{4}$, Samuel Nowakowski ${ }^{5}$, Cristian Perra ${ }^{6}$, Tony Ward ${ }^{7}$ \\ and all ELLEIEC partners \\ 1) Université de Lyon I, France, hamed.yahoui@univ-lyon1.fr \\ 2) Université de Rennes I, France, Olivier.bonnaud@univ-rennes1.fr \\ 3) Université Bordeaux, France, helene.fremont@ims-bordeaux.fr \\ 4) Copenhagen University College of Engineering, Denmark, afr@ihk.dk \\ 5) Université de Nancy I, France, samuel.nowakowski@nancy-universite.fr \\ 6) University of Cagliari, Italy, cperra@diee.unica.it \\ 7) University of York - United Kingdom, Aew6@york.ac.uk
}

\begin{abstract}
This paper presents the objective and current state of the ELLEIEC [1] project (Enhancing Lifelong Learning for the Electrical and Information Engineering Community). The implementation of the Bologna process offers us an opportunity to create a European dimension to our EIE (Electrical and Information Engineering) Degrees in the World Wide education area by convergence of our curricula and strengthening the links and sharing of resources between European Higher Education Institutions.
\end{abstract}

Keyword - ELLEIEC TN, Electrical and Information and Engineering, Entrepreneurship Centre, Lifelong learning

\section{INTRODUCTION}

ELLEIEC is the follow-up of EIE-Surveyor TN [2-3] which aims at acting both as an observatory and a proposition force for evolution, in the interdisciplinary fields of Electrical and Information Engineering (EIE), of engineering curricula through the implementation of the Bologna process. The first objective of the ELLEIEC project is to develop a virtual European Centre for Entrepreneurship Education in Electrical and Information Engineering with an internal e-learning assessment offer, which will be a reference point for any applicant in the Lifelong Learning framework. The second objective is to study, through an experiment and a survey, of the mutual recognition process to gather information on good practice in the design of International cooperation at both master and bachelor levels. At the same time, a study will be undertaken across different European countries on how to incorporate the accreditation of prior lifelong learning into the $\mathrm{PhD}$ process, which will allow engineers within a company to move back into education to continue their studies and prepare and validate a doctoral thesis. This benchmark will be used to analyse the recognition systems required to ensure the appropriate credit transfer for prior informal learning.

\section{PROJECT OBJECTIVES}

For an educational institution, giving recognition and appropriate ECTS credits for an intensive training or a web based course, which uses its own internal pedagogical resources, is a common occurrence. However, with an Erasmus mobility agreement, because external learning resources are involved the validation and ECTS credit assignment process can result in a much longer pedagogical and administrative process. It should also be noted that in this case, it is the sending institution that determines the number of ECTS credits awarded and records the result for its own degree. The Erasmus process works best when, after a long shared experience for formal learning, a strong partnership is developed between two institutions. With Lifelong Learning the recognition problem is more concerned by accrediting non-formal learning and informal knowledge gained from external sources. With the Lifelong Learning programme, Europe has shown the importance of providing a framework for the identification and validation of these 'invisible' learning outcomes. Arising from this initiative, a large number of European projects have been launched in the two following topic areas:

- Inventory of validation of non-formal and informal learning has been produced with Cedefop, with a detailed survey of developments in European countries,

- European Qualification Framework for lifelong learning (EQF).

Unfortunately, many institutions continue to undertake the long process of evaluation of any external training without being fully aware of the availability of this new European process. 
Developing a system which will give a learner the opportunity to take advantage of external learning provided with full ECTS recognition will bring to Europe a valuable diversity and specificity in its qualification framework.

The original idea of the ELLEIEC project was to conduct some experimental work to provide appropriate benchmarks and to undertake a set of surveys on relevant topics across various European countries. All the activities undertaken in this project follow the objectives:

- $\quad$ to facilitate the faster exchange of information on educational systems by means of a central Gateway,

- to standardise the recognition of diplomas, other qualifications and study periods,

- to stimulate student and staff exchange and cooperation between start-up initiatives,

- to develop joint mobility networks and teaching materials,

- to participate in mutual quality assessment of elearning tools.

ELLEIEC [1] will principally deal with the following types of informal learning which are increasingly becoming available in HIE, companies, start-up and work-shop seminars \& conferences:
- Web based courses: with the evolution of the internet, teachers increasingly are designing valuable web courses,

- Vocational Intensive course: mainly dedicated to employer learner and are generally of less than one-week duration.

In general these kinds of informal learning, which have a workload range of close to 1 or 2 credits are not considered for inclusion in a classical formal course in HIE. To take account of this fact, the main output of task 3 is the design of a Virtual Centre for Enterprise Centre of Entrepreneurship. The Virtual Centre will provide learners with the opportunity to develop their competence in small, bite-sized pieces as and when they need them or as part of a planned overall learning strategy.

\section{PROJECT APPROACH}

ELLEIEC TN comprises 60 partners all in the field of electrical and information engineering who are involved in a range of different tasks. Based on the experience gained from our last TN (EIE-surveyor) and the implementation of the Bologna process, we are now studying and undertaking some experiments (Figure 1) to define a more suitable structural framework to improve European incoming mobility and international partnerships taking account of the lifelong learning issue and recognition problem.

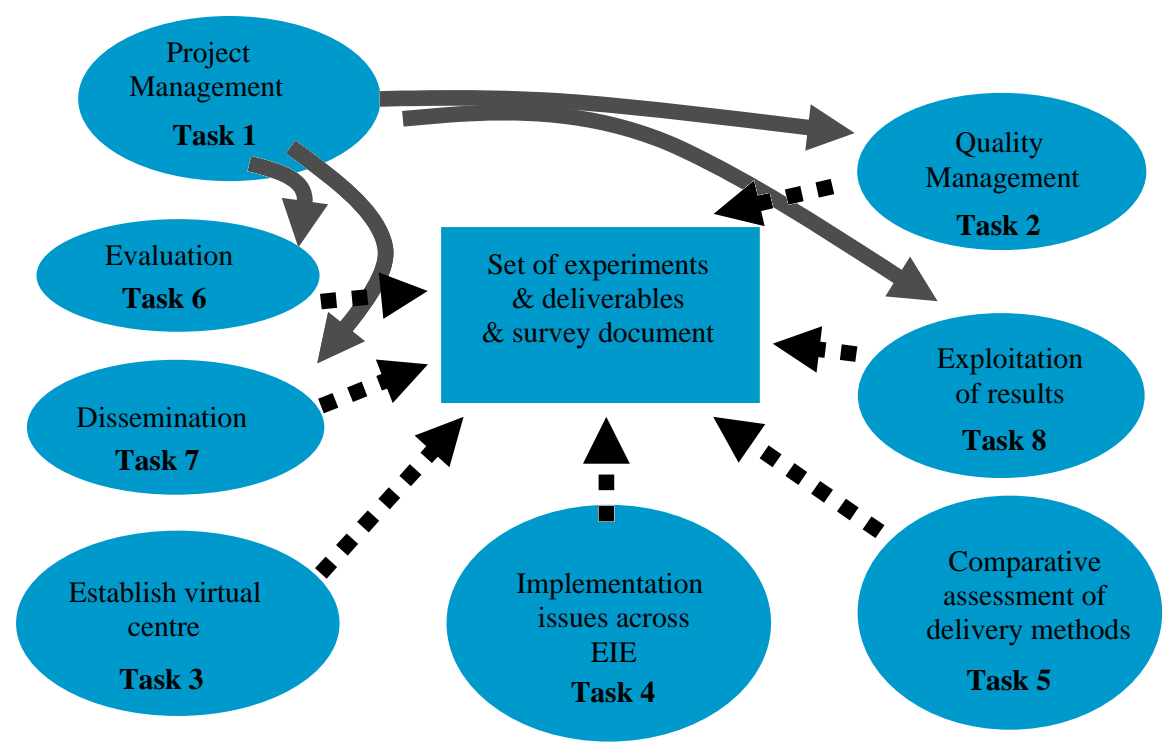

fig 1: ELLEIEC project structure

There are three main development tasks $(3,4,5)$ and a set of managing tasks $(1,2,6,7,8)$. This partitioning ensures that we have the correct organisational structure to achieve our goals. All partners are involved in at least one of the 3 main tasks.
Task number:

1. Project Management

2. Quality Management

3. Establish virtual centre (main task)

4. Implementation issues across EIE (main task) 
5. Comparative assessment of delivery methods (main task)

6. Evaluation

7. Dissemination

8. Exploitation of results

The consortium has been carefully chosen to provide the range of skills and resources required to bring the Virtual Centre for Enterprise into reality. The University of York brings access to an existing data base of enterprise learning resources, access to a large student enterprise society, links to its partner UK universities of Leeds and Sheffield, access to enterprise assessment instruments through its Education for High Growth Industries project network, and access to its Skills forge competence management tool. To ensure the success of the project, we have, in our consortium, a set of relevant partners providing us a valuable platform for our experiments:

- An International Bachelor,

- An Erasmus Mundus Master,

- Heads of Doctoral Schools,

- Start-ups and incubator agencies (associated partners),

- Members of accreditation board,

- Experts in assessment of e-learning tools,

- Associated partners from industry and institutions outside of Europe,

- Providers of e-learning centre.

Taking account of this spread of partners we will share the expertise of the various partners to launch a first set of ICN (International Curricula Network) experiments which were carried out during the 2009/2010 academic year in a real situation (figure 2).

An ICN is a set of Curricula and Course Providers, 'partners', who agree to provide shared curricula or program (partially or totally) in a specialist technical subject. The curricula entity in the ICN will certify the level and number of credits attributed to the IM course offered by the provider body for its own degree. The provider entity is the owner of the IM used in the ICN and it is their prerogative to set the conditions for joining this course. Ideally, these shared curricula should be recognized at the accreditation level, but the process can be difficult in some cases. In order to initiate the ICN, we consider two pragmatic cases:

1. Cross recognition of "curricula" (learning outcomes, competences, Tuning approach), which is the fact when at least two institutions agree on common modules for an ERASMUS exchange (exchange of students and/or exchange of teachers),

2. Shared recognition of modules, which is the case when a set of modules is developed and implemented within the frame of a program (here, distant modules can be used).

Concerning this second point, we can consider the practical use of a module in various ways:

- Distant Course without tutor,

- Distant course with distant tutor,

- Distant course with local tutor,

- Local course.

The last role of the ICN is to act as a "pedagogical committee" in order to identify good approaches in the setting of existing or new LLL curricula.

From an implementation point of view the IM could be available as a simple link in the ELLEIEC website or in the ELLEIEC IM database (depending of the owner). 


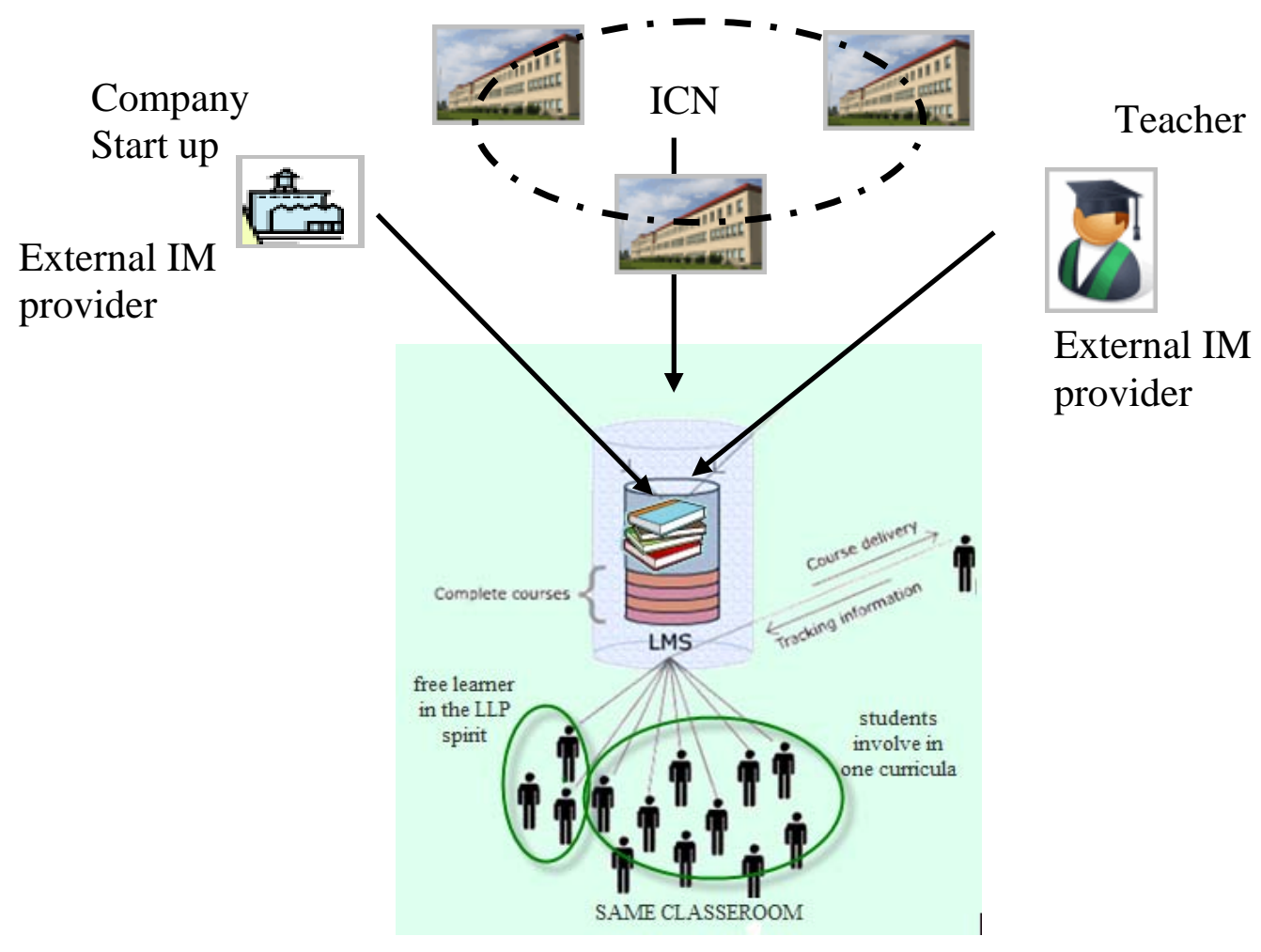

Experiments:

fig 2: ICN composition: built with the potential of different ELLEIEC partners.

Experiments will be used to simulate in a real situation a process concerning each of our task objectives. For some experiments, ELLEIEC partners and some BMD degrees (BMD, Bachelor Master Doctorate), together with students, associated partners and pedagogical resources will be involved. They will take place during an academic year or during some dedicated events. A large part of the activities of the three main tasks $(3,4,5)$ will be built around these experiments, as shown in Figure 3 (complete description of each experiment will be given on the three main tasks paragraph).

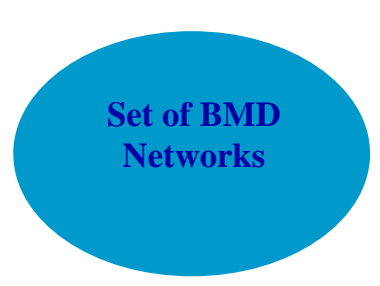

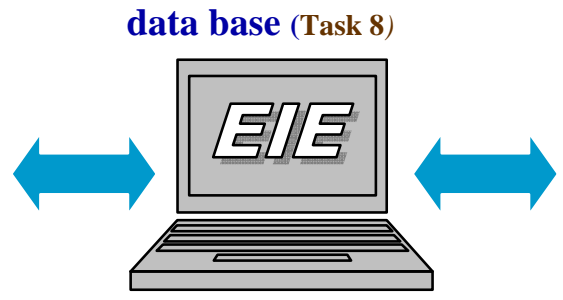

Centre of Knowledge
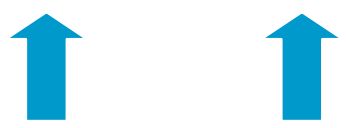

Job market needs Recognition

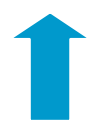

E-learning specification E-learning assessment

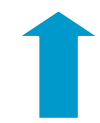

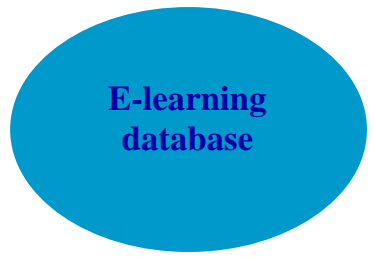

(Task 4)

fig 3: Interaction between tasks and Experiment

Experiments will help us to identify the main problems that need to be addressed before the proposed process can be implemented. A set of questionnaires, which will take advantage of all particularities and experiences of European countries involved in ELLEIEC TN, will be used in these experiments. As an added value, some experiments will focus their activities around the EIE (Electrical and Information Engineering) discipline with a special attention to innovative degrees corresponding to the pedagogical needs for developing new skills for new jobs. 


\section{CURRENT PROJECT OUTCOMES}

One of the two main outcomes of our first term of the project has been to design the entrepreneurship centre and to propose the ICN concept, which was not listed as a specific outcome at the beginning of the project. The entrepreneurship centre will be explained in a more detailed manner in the task 3 paragraph. In this first phase, the ICN concept in its first draft has been elaborated and some experiments have been conducted during the last academic year with collaborative work between tasks among various European countries.

After making a survey on the different platforms of web based or intensive course available on the net, it was noted that none of them were offering ECTS recognition in bite-sized pieces. This fact is easy to understand as we know that each institution provides either its pedagogical courses or uses a bilateral agreement to recognise external courses for 'large' size course modules. In the framework of the ELLEIEC project, we want to give access to some International Modules (IM: web based or intensive training classroom course) that are used already either in some existing bilateral agreement or in some informal situation and study their use, ensuring ECTS recognition, within an International Curricula Network (ICN) via the ELLEIEC project experiment and survey.

The organization of the work around the experiment is divided in three main scientific tasks:

- WP3 is in charge to design the entrepreneurship centre as an IM provider,
- WP4 proposes some curricula to analyze the recognition issue at BMD level Bachelor Master and Doctoral level,

- WP5 proposes an IM course framework guideline which will be used to specify the agreement between an ICN and an IM provider.

WP3: the overall objective of this task is to develop a sustainable Centre that will provide learners with enterprise education across Europe for the foreseeable future in byte-sized chunks[4]. To this end, development and growth have been designed specifically to be steady, progressive and careful for the benefit of the long-term success. To ensure this long-term success establishment of the Virtual Centre VCE [5] (Virtual Centre of Entrepreneurship) will be in three stages, the first stage will be a small pilot trial designed to test the learner registration, security and data protection parts of the system; the second stage will be a larger scale delivery designed to test how the system and its administrative systems respond to volume usage; the final stage will be the full scale delivery of the system. Stages 1 and 2 are addressed in this short-term section while stage 3 is described in the long-term targets section.

The initial learning resources will be provided in English although actions to translate them into a range of languages will be started early in the project.

The first design (figure 4) of the VCE has been done and is available at url: http;//vce.york.ac.uk.

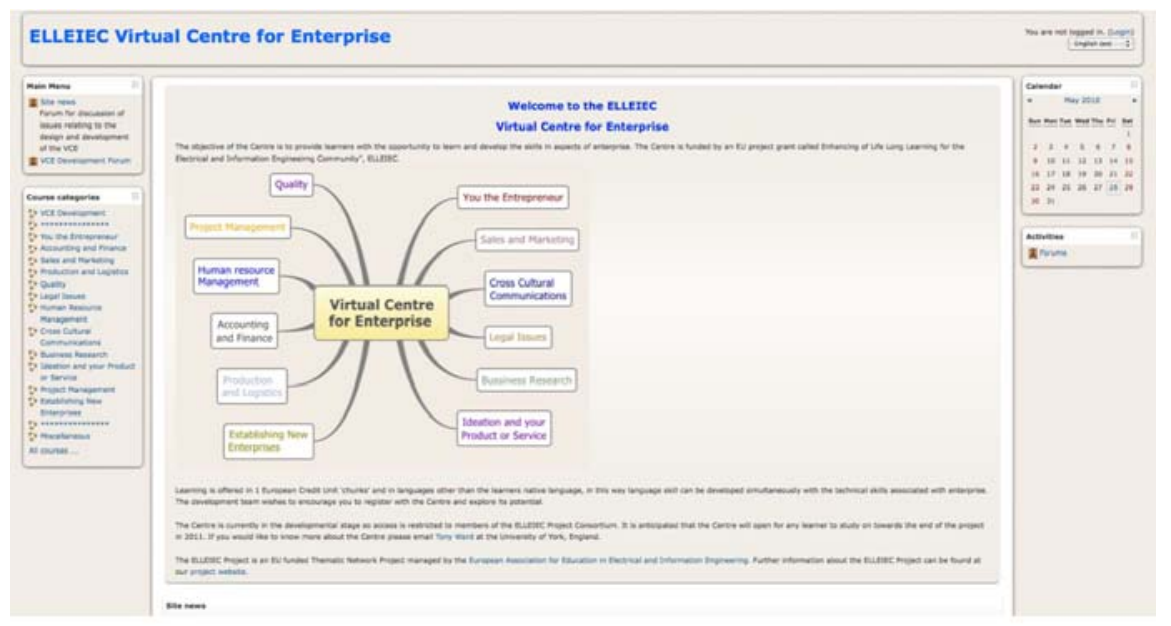

Fig 4: Top Section of VCE Welcome Page

WP4: this work package undertakes an action to measure the need of competencies recognition through a set of some curriculum benchmark and a survey of the different frameworks used to take account of the lifelong learning accumulation system.
The study will focus on the Energy, Wireless network, Imaging \& Computer Vision \& robotics disciplines as there are parts of some currently running bachelor and master degrees within ELLEIEC partners. In a secondary way, the emerging of new challenges like 
market globalization, technology progress and growing unemployment will lead to a primordial adaptation of our classical curricula to participate to the competitiveness, innovation and attractiveness of the European area by enhancing the industrial culture and lifelong learning process inside our institutions.

A special sub task will describe the new missions and evaluation criteria that will be used for doctoral studies after harmonization following the Bologna process. Special attention is devoted to studies in the field of Electrical and Information Engineering based on experience of a graduate school in France.

WP5: A key part of work package 5 will be the quantitative assessment of the effectiveness of the bitesized non-classical learning available compared to similar learning by conventional teaching methods.

\section{Comparing traditional Learning and E-Learning}

There is an argument that traditional learning is the best way of maintaining a learning process. Ross and Schulz [6] suggest that computer aided instruction may not be the most appropriate method of learning for all students. Other models are always considered to be inferior or less efficient. However, there is no evidence to support this argument, and research shows that technology-supported models are at least as good as traditional learning methods [7].

The educational benefit is not uniform across all learners in the class owing to the differing entrepreneurial aspirations of students, with some having no aspirations at all. The assessment of these measures is via a questionnaire given to the learners before and after the educational experience. These questionnaires will be built into the Virtual Centre such that all learners will be required to complete a questionnaire upon registration with the Centre and then post questionnaires periodically through their studies. The analysis of the pre and post questionnaires will enable the change in the entrepreneurial measures to be determined. The results will be of use to the project as it will, over a period of time, enable us to build a picture of the relative effectiveness of the available learning resources and their continuous improvement.

Several Cases of study have been implemented with students from around Europe:

Spain: they are using mobile technology to deploy a more interactive delivery method where students employ Tablet PCs to both follow instructor presentations and to solve in-class active learning exercises. Additionally, the ease of soliciting responses from students enables instructors to integrate formative assessment into classroom practices and providing immediate feedback.

$\mathrm{UK}$ : this test aims to investigate the reasons to reveal and examine whether or not there is a real point in the methods by which mathematics is delivered in engineering subjects. It aims to find out whether new emerging e-learning tools are really a support or an obstacle when teaching mathematics. A survey is carried out among final year Bachelor degree Digital Signal Processing students to obtain their opinion on the subject matter.

An overview of all running experiments from many European countries is given in table 1.

\begin{tabular}{|l|l|l|}
\multicolumn{1}{|c|}{ Type of Experiments } & \multicolumn{1}{|c|}{ Country } & \multicolumn{1}{c|}{$\begin{array}{c}\text { Number of } \\
\text { involved } \\
\text { students }\end{array}$} \\
\hline $\begin{array}{l}\text { A Practice in Using E-Portfolio in a Higher Education } \\
\text { Course Taught at Distance }\end{array}$ & Izmir University, Turkey & $\begin{array}{l}22 \text { students: } 7 \\
\text { undergrad, } 15 \\
\text { grad }\end{array}$ \\
\hline $\begin{array}{l}\text { Enhancing learning by using Tablet PCs in a networked } \\
\text { classroom }\end{array}$ & $\begin{array}{l}\text { Universidad Politécnica de } \\
\text { Valencia, Spain }\end{array}$ & $20-20 / 30$ \\
\hline $\begin{array}{l}\text { EURO-QLIO - European Virtual Campus } \\
\text { CISCO Courses }\end{array}$ & Université Nancy 1, France & 51 \\
\hline $\begin{array}{l}\text { MEDICAL INFORMATION SYSTEMS } \\
\text { Handbook for Laboratory Exercises and Self testing }\end{array}$ & $\begin{array}{l}\text { University of Rousse, Bulgaria } \\
\text { University, Bulgaria }\end{array}$ & 15 \\
\hline Blended Learning in Guided Propagation and Antennas & $\begin{array}{l}\text { Institut Superior do Lisboa, } \\
\text { Portugal }\end{array}$ & $70 /$ year \\
\hline
\end{tabular}




\begin{tabular}{|l|l|l|}
\hline \multicolumn{1}{|c|}{ Type of Experiments } & \multicolumn{1}{|c|}{ Country } & \multicolumn{1}{|c|}{$\begin{array}{c}\text { Number of } \\
\text { involved } \\
\text { students }\end{array}$} \\
\hline Clickers & Riga University, Latvia & \\
\hline E-learning versus classical one & $\begin{array}{l}\text { Juan Carlos, University of Vigo, } \\
\text { Spain }\end{array}$ & 10 \\
\hline PPT course & $\begin{array}{l}\text { Northumbria University, } \\
\text { Newcastle, UK }\end{array}$ & 20 \\
\hline E-learning versus classical one & $\begin{array}{l}\text { Michael Hoffman, Ulm } \\
\text { University, Germany }\end{array}$ \\
\hline
\end{tabular}

Table 1: list of Experiments

A work package "Exploitation of results", task 8, has provided the web software assistance to launch the first phase of experiments and to produce the specification of the whole Web portal gateway with respect to the three main tasks needed until the end of the project.

\section{CONCLUSIONS AND PERSPECTIVES}

The ELLEIEC project has reached a first step by designing a demonstrator for the ICN concept (International Curricula Network) and the VCE (Virtual Centre of Entrepreneurship).

An analysis of the results achieved during the mid term of the project will help to set correctly the next objectives. Based on our first results, the action of the ELLEIEC consortium will work on the interaction between the three main development tasks to provide a Business model framework for the ICN concept and the VCE, gathering experience from recognition assessment and new informal bite sized learning experiments and surveys. The real challenge of the ICN and the VCE will be to encourage all involved associated and ELLEIEC members to use the courses online for their own degree with ECTS recognition to ensure its sustainability. Additional sub task will focus on:

- Lifelong learning application to PhD level,

- BMD advertising position offer,

- Database of paper outcomes.

- Analysis on New skills for new jobs in EIE.

The next challenge will be to disseminate the proposed model among university institutions.

\section{Acknowledgments}

The authors wish to thank the European Commission for the grant to ELLEIEC in the Life long Learning Programme, the Executive Agency for its help and all the partners of the project for their contribution.

Project Number: 142814-LLP-1-2008-FR-ERASMUSENW

Instrument type: ERASMUS NETWORK

\section{References}

[1] ELLEIEC: Enhancing Lifelong Learning for the Electrical and Information Engineering Community, http://www.elleiec.eu/

[2] Results of the EIE-Surveyor project, coordination: JeanMarc THIRIET (ISBN 2-9516740-2-3). (ISBN - 29516740-3-1) (ISBN - 2-9516740-4-X).

[3] H. Yahoui, O. Roesch, J.M. Thiriet, M. J. Martins and O. Bonnaud, "Evolution of master degree in Europe: An overview of the European programme available in electrical and information engineering", Conf. CD-ROM Proceedings (6 pages); EIEEIE'05 Conference, Lappeenranta, Finland, June 2005.

[4] C. Perra, H. Yahoui, T. Ward. An Entrepreneurship Centre in the lifelong learning spirit, Page(s): IEEEITHET 2010, April 2010, Turkey

[5] url: http;//vce.york.ac.uk

[6] Ross, J., Schulz, R.(1999). Can computer-aided instruction accommodate all learners equally?, British Journal of Educational Technology, Vol. 30 No. 1, pp. 5-24.

[7] Rashty, D. Traditional Learning vs. eLearning, Mount St. Mary's College. [Online]. (URL http://www.msmc.la.edu/include/learning_resources/). (Accessed August 2010). 